\title{
Implementing large Foot and Mouth Disease vaccination programmes for smallholder farmers: lessons from Lao PDR
}

\section{Original Paper}

Cite this article: Nampanya S, Khounsy $S$, Abila R, Windsor PA (2018). Implementing large Foot and Mouth Disease vaccination programmes for smallholder farmers: lessons from Lao PDR. Epidemiology and Infection 146, 2086-2095. https://doi.org/10.1017/ S0950268818002443

Received: 27 April 2018

Revised: 4 July 2018

Accepted: 30 July 2018

First published online: 23 August 2018

Key words:

Developing countries; Foot and Mouth Disease; large ruminant health; vaccination

Author for correspondence:

S. Nampanya,

E-mail: snam7362@uni.sydney.edu.au

\section{S. Nampanya ${ }^{1}$, S. Khounsy ${ }^{2}$, R. Abila ${ }^{3}$ and P. A. Windsor ${ }^{1}$}

${ }^{1}$ The University of Sydney, Sydney School of Veterinary Science, Camden, NSW 2570, Australia; ${ }^{2}$ Department of Livestock and Fisheries, Ministry of Agriculture and Forestry, Vientiane Capital, Lao PDR and ${ }^{3}$ OIE Sub-Regional Representation for South-East Asia (SRR-SEA), Bangkok, Thailand

\begin{abstract}
This study assessed smallholder finances and their attitudes towards the Foot and Mouth Disease (FMD) vaccination programme, when 1620000 vaccine doses were provided for strategic administration in large ruminants in FMD 'high-risk' areas in Laos between 2012 and 2016. Farmers $(n=168)$ in the provinces of Xayyabouli (XYL), Xiengkhoung (XK) and Huaphan (HP), were interviewed. Over $91 \%$ of the farmers responded that their livestock were vaccinated for FMD, with over $86 \%$ ranking FMD vaccination as a good or very good intervention. No FMD cases were reported from the vaccinated provinces after May 2013. Examination of the total income per household in XYL, XK and HP indicated earnings of US\$5060 $( \pm 650)$, US $\$ 4260( \pm 294)$ and US\$1691 $( \pm 676)$, respectively $(P=0.001)$, with $23 \%$, $28 \%$ and $68 \%$ of the total incomes from annual sales of large ruminant, respectively. Of the farmers in XYL, XK and HP, 83\%, 93\% and 70\% $(P=0.009)$ said their annual income increased compared with 2012 , and $47 \%, 64 \%$ and $41 \%$, respectively $(P=0.005)$, indicated this increase was from additional large ruminant sales. The study indicated that this large FMD vaccination programme was well regarded by participating farmers and may have provided satisfactory suppression of the disease in Laos, despite not achieving the preferred vaccination coverage. Continuation of the vaccination programme in FMD high-risk areas is suggested as desirable.
\end{abstract}

\section{Introduction}

Foot and Mouth Disease (FMD) is one of the most important global transboundary livestock diseases, compromising sustainability in livestock production and trade. With the majority of FMD outbreaks occurring in developing countries where veterinary capacities are sub-optimal and uncontrolled spread of FMD occurs, continuing epidemics of FMD have been described as a failure of the global food security system $[1,2]$. In the Southeast Asian Region (SEA) including the Greater Mekong Sub-region (GMS), FMD mainly affects large ruminants and occasionally pigs, impacting on the livelihoods of smallholder farmers and national economies, particularly in the Lao People's Democratic Republic (Lao PDR or Laos) [3, 4]. Although the FMD viruses (FMDv) have seven distinct serotypes (A, O, C, Asia 1 and SAT 1, 2 and 3), the co-circulation of multiple serotypes within zones of increasingly dynamic regional animal trade, led to groupings of isolates and countries into seven regional 'pools' $[5,6]$. FMDv pool 1 includes the GMS, where recent epidemics have involved mostly isolates of O (Cathay, SEA Mya-98, Pan Asia), A (SEA 97) and less commonly Asia 1 serotypes [3, 7-9], although recently, outbreaks due to O/ME-SA/Ind-2001d and A serotypes have been emerging [10] suggesting that transmission of FMDv serotypes between pools is increasing.

In SEA, the inclusion of FMD vaccination activities in FMD control and eradication programmes proved successful in Indonesia and the Philippines [11]. However, control of endemic FMD in other SEA countries, particularly within the GMS where countries share porous borders with other FMD-endemic countries, is challenging [12]. Laos shares borders with five FMD-affected countries and is positioned on a major thoroughfare for transboundary livestock movements in the GMS, particularly from Thailand and Myanmar to China and Vietnam [9, 13], with over a million cattle now exported from SEA to China annually [14]. The Southeast Asia Foot and Mouth Disease (SEAFMD) campaign was launched in 1997, then expanded to include China (SEACFMD) in 2007, providing a 'Roadmap' that initially proposed a goal of achieving FMD freedom in SEA by 2020 [12]. The SEACFMD Roadmap describes the need for participating countries to improve their surveillance, early detection and reporting, rapid disease responses, plus contribute to improved understanding of livestock movement and trade in the region $[9,11,12]$. Gaining support for the SEACFMD programme from international donors to foster appropriate national animal health policies and cooperative leadership, plus influencing livestock stakeholders and especially smallholder farmers to 
participate in vaccination programmes and improve biosecurity, is considered crucial for FMD control programmes to be successful in the GMS [14]. Improved understanding of both the financial constraints and opportunities of smallholder farmers, plus their attitudes towards FMD vaccination interventions, is considered important for achieving sustainability of FMD control in SEA. The socio-economic impacts of FMD on households likely influence the participation of farmers in vaccination programmes. This in turn has consequences for the sustainability of local and regional livestock trade, the developing livelihoods of farmers, plus consumer preferences for livestock products, thus impacting on regional national economies.

Between January 2012 and December 2016, the Department of Livestock and Fisheries (DLF) in the government of Laos received annual donations of FMD bivalent $\mathrm{O}$ and $\mathrm{A}$ and monovalent $\mathrm{O}$ serotype vaccines (initially $<200000$ doses in 2012, increasing to 400000 doses in 2015). This occurred mainly through the Stop Transboundary Animal Diseases and Zoonoses (STANDZ) programme funded from Australia and managed by OIE (The Office International des Epizooties or the World Organisation for Animal Health) Sub-Regional Representation for South East Asia located in Bangkok, Thailand, although additional vaccines were contributed by the Japan Trust Fund (JTF) of the OIE Regional Representation for Asia and the Pacific. The donated vaccines were used extensively in northern provinces, districts and villages of Laos that were considered as 'high-risk' areas for FMD transmission, particularly FMD 'hotspots' (areas where repeated FMD outbreaks have been recorded) and 'nodes' (areas where extensive animal trading occurs), such as transit routes for transboundary movements [9]. This programme was entitled 'The Foot and Mouth Disease Vaccination Project' and implemented in January 2012 in northern Laos, with expansion in early 2015 to include provinces in central Laos.

Following the completion of the vaccination programme in December 2016, an assessment of smallholder finances and their attitudes towards The FMD Vaccination Project was conducted. The study included detailed examination of farmer livelihoods to assess the role of livestock on household finances plus the roles of women in FMD control programmes. The study aimed to provide recommendations on future FMD control programmes in Laos and beyond, potentially providing benefits to the many nations at risk of endemic FMD in the SEACFMD network. This information is important to policy makers, livestock stakeholders and smallholder farmers, particularly where vaccination and biosecurity interventions are expected to be delivered by developing regional veterinary services tasked with providing effective and sustainable FMD control and eventually, eradication.

\section{Methods}

\section{Survey location and farmer interview}

The study used a mix of participatory approaches, building on tools developed for a recently completed study in northern Laos and those described in OIE regional office research guidelines [9]. The survey was conducted in January and February 2017, in the three northern provinces of Xayyabouli (XYL), Xiengkhoung (XK) and Huaphan (HP) by a survey team of three persons, including the lead investigator, and a provincial and district staff member. These provinces were randomly selected from a list of 10 provinces participating in The FMD Vaccination Project. In each province, two districts $(n=6)$ and four villages (two villages per district, $n=12$ ) were randomly selected, based on the project participation list and consultations with local livestock authorities. Criteria for inclusion were they: (i) have been participating with The FMD Vaccination Project since commencement of the programme in January 2012; (ii) have considerable trading of large ruminants into and from the village; and (iii) have year-round vehicular access.

In each interviewed village, the interviews were conducted in two parts, each with different sets of questions that took approximately 45-60 min per interview (Supplementary material 1). The selection process for interviewees necessarily used a degree of convenience selection, particularly to accommodate farmer availability. However, to ensure that representative data were obtained from each village, the survey team facilitated detailed discussions with the village chief, elders and village veterinary worker prior to household selection.

First, the village chief, elders and village veterinary workers were interviewed 'face to face' with information collected to provide an overview of livestock health and production and recent and current vaccination programmes in the village. The questionnaires were designed to achieve satisfactory discourse analysis, as the low levels of literacy and ethnicity issues required a conversational format to encourage a free flow of information. The ensuing discussion obtained the total number of households in the village, the number of households with livestock, the number of households with livestock where a female headed the household, the number of farmers with livestock participating in the FMD vaccination, and records of cattle and buffalo vaccinated for FMD in the last round of FMD vaccinations. Due to limited resources for regular data collection and the dynamic nature of some data (e.g. number of calves), some information from some villages used an agreed estimated number derived during the detailed discourse.

Second, 12-16 smallholder farmers with cattle and buffalo in each village were interviewed 'face to face' $(n=168)$ with criteria for inclusion being: (i) the participating farmers have large ruminants; they may or may not have participated in The FMD Vaccination Project; and (ii) be willing to participate in the survey. Interviews included open questions followed by probing questions to clarify the answers and obtain the complete information required. Questions covered household financial status parameters (e.g. annual household incomes, number of large ruminants, number of animals vaccinated for FMD), farmer knowledge and attitudes on FMD and basic biosecurity practices, plus opinions on The FMD Vaccination Project.

\section{Review of The FMD Vaccination Project and FMD outbreak records}

FMD vaccination and FMD outbreak records between 2012 and 2016 available at the provincial livestock section and as reported to the DLF in Vientiane and the DLF regional office in Luang Prabang (LPB), were examined.

\section{Data management and analysis}

The smallholder farmer interview data were transcribed into spreadsheets in Microsoft Excel 2010. Their annual household incomes were classified according to livelihood activities, including income from cropping, small livestock animals (pigs, goats and poultry), large ruminants (buffalo and cattle) and other activities, including labour and trading, designated as 'other' as 
previously described [3]. For the knowledge questions, responses were assessed based on answer guidelines developed by the research team. A correct answer was given one mark, and an incorrect or an 'I-do-not-know' answer was given a zero mark. Scores were added to obtain knowledge scores for each interviewed farmer with total marks of 7 . Abilities of each farmer to answer questions on FMD correctly from the description of clinical signs were also obtained.

Quantitative variables (annual household income and number of large ruminants) were analysed using a restricted maximum likelihood (REML) in Genstat 14th edition statistical programme (VSN International), with province (XYL, XK and HP), gender of respondents (male vs. female) and gender of household large ruminant caretaker categories (male and female) as a fixed effect, and farmer identification as a random effect. Linearity, homoscedasticity and normality assumptions were checked by diagnostic plots of standardised residues of the quantitative traits on model checking options in REML. Dichotomous qualitative variables (yes/no answers) on responses to farmer attitudes and practices towards The FMD Vaccination Project were analysed using a $\chi^{2}$ test. Comparisons between surveyed location (XYL, XK and HP) and gender of livestock caretaker and respondent categories were determined.

Data obtained at the village level included the means and standard errors of the number of: total households per village, households with livestock, households with livestock participating with The FMD Vaccination Project, the total livestock present and the total of livestock vaccinated for FMD, were summarised.

Data on FMD vaccination included the number of participating provinces, districts, villages and livestock vaccinated for FMD, from January 2012 to December 2016. The vaccination district and village participation (vaccine coverage) rates were determined based on the number of participating districts and villages, and the total number of districts and villages of the 10 participating FMD vaccination provinces, including Phongsali, Bokeo, Luang Namtha, Oudomxay, LPB, XYL, XK, HP, Vientiane and Xaisomboun [15]. It was unfortunate that the vaccination coverage rate at the animal level could not be accurately determined due to confounding of statistics [16] on the total number of adult animals in the participating provinces and districts.

\section{Results}

\section{Numbers of interviewed farmers and their household rice production}

The number of interviewed farmers and their household rice production by province categories were tabulated (Table 1). There were 168 farmers interviewed, with $95 \%$ of farmer respondents indicating that they produced enough rice for their household annual consumption.

\section{Smallholder household annual and livestock incomes}

There were significant differences in the farmers' total household annual incomes and income from cropping between the province categories, but no significant differences between the gender of livestock caretaker categories (Table 2). The mean total income per household in XYL, XK and HP were US\$5060( \pm 650$)$, US $\$ 4260( \pm 294)$ and US\$1691 $( \pm 676)$, respectively $(P=0.001)$, with $23 \%, 28 \%$ and $68 \%$ of the total incomes from the sale of large ruminants. Of the total interviewed farmers in XYL, XK and $\mathrm{HP}, 83 \%, 93 \%$ and $70 \%(P=0.009)$ said their annual income had increased compared with 2012, and $47 \%, 64 \%$ and $41 \%$ $(P=0.005)$, respectively, indicating that their annual income had increased from the sales of additional large ruminants.

There were no significant differences in the mean number of large ruminants per household between province and gender of livestock caretaker categories. The mean numbers of large ruminants per household were $10( \pm 2.8), 12( \pm 1.3)$ and $14( \pm 2.7)$ in $\mathrm{XYL}, \mathrm{XK}$ and HP $(P=0.7)$, respectively. Of the total respondents in XYL, XK and HP, 73\%, 85\% and $87 \%$, respectively, indicated that primary caretaker for their household large ruminants was either an adult or elderly male $(P=0.2)$. Of the farmers in XYL, XK and HP, 92\% $82 \%$ and $67 \%$ said that their total numbers of large ruminants had increased compared with $2012(P=0.004)$ with the mean number increasing by $5( \pm 4), 2( \pm 2)$ and $3( \pm 2)$ heads per household, respectively.

\section{Farmer knowledge and attitude towards The FMD Vaccination Project}

There were significant differences in farmer knowledge scores between province categories, but not between gender of respondent categories (Table 3). Of the interviewed farmers in XYL, 44\% were able to answer FMD questions correctly $(P<0.001)$, with $78 \%$ of the interviewed farmers in this province scoring $\leqslant 4$ of the total of 7 marks $(P<0.001)$.

There were no significant differences in farmer responses on their ranking of FMD vaccination and their interest in FMD vaccination, both by province and gender of respondent categories. Of the interviewed farmers, over $86 \%$ ranked the FMD vaccination activities as good and very good, with only one farmer in XK mentioning that the vaccination was not unacceptable $(P=$ 0.4 , Table 3). Almost all farmers (100\% in XYL, $96 \%$ in XK and $98 \%$ in HP) said they were still interested in the vaccination if some payment was required $(P=0.3)$, and indicated they were able to contribute approximately US $\$ 0.5$ per dose (although the FMD vaccine and administration cost per unit is between US $\$ 2.1-2.5)$. In XYL, 92\% of farmers said that their livestock were vaccinated for FMD in the last 6 months $(P=0.2)$, although about $75 \%$ of the interviewed farmers in this province said that their stock were regularly vaccinated for FMD every 6 months in the last 4 years $(P=0.03)$.

\section{Village-level FMD vaccination participation}

The mean total households per village in the surveyed areas was $113( \pm 78)$, with $90( \pm 55)$ households with cattle and buffalo (Table 4). Of the total household with large ruminants, $60 \%$ $( \pm 9)$ participated in The FMD Vaccination Project, with $62 \%$ $( \pm 16)$ of the adult cattle and buffalo aged over 6 months vaccinated for FMD in the last round of vaccination. The village chief, village veterinary workers and elders all confidently said that the last outbreak of FMD in their villages occurred in early 2012.

\section{Review of the FMD vaccination programme and FMD outbreaks}

The record of available vaccines, source and serotype of vaccines provided for the programme were tabulated (Table 5). All vaccines provided from the STANDZ programme were bivalent serotypes $\mathrm{O}$ and $\mathrm{A}$ (Merial Company Ltd, Berkshire, UK) and vaccines from the JTF programme included both monovalent $\mathrm{O}$ and A serotypes (Merial Company Ltd). 
Table 1. Survey location, number of interviewed farmers and their household rice production

\begin{tabular}{|c|c|c|c|c|}
\hline Variables & XYL & $\mathrm{XK}$ & HP & Overall \\
\hline \multicolumn{5}{|l|}{ Surveyed location } \\
\hline No. interviewed districts & 2 & 2 & 2 & 6 \\
\hline No. interviewed villages & 4 & 4 & 4 & 12 \\
\hline No. interviewed farmers & 59 & 55 & 54 & 168 \\
\hline Mean size of farmer hh (pers./hh) & $5 \pm 1.4$ & $6 \pm 1.6$ & $8 \pm 3.1$ & $6 \pm 2.4$ \\
\hline Mean no. females in hh (pers./hh) & $3 \pm 1$ & $3 \pm 1$ & $4 \pm 2$ & $3 \pm 1$ \\
\hline \multicolumn{5}{|l|}{ Rice production } \\
\hline Rice produced (tone/hh) & $3.7 \pm 3.0$ & $4.7 \pm 2.0$ & $3.2 \pm 1.6$ & $3.9 \pm 2.4$ \\
\hline
\end{tabular}

XYL, Xayyabouli; XK, Xiengkhoung; HP, Huaphan; hh, household.

Mean \pm standard deviation.

The number of provinces, districts and villages participating in The FMD Vaccination Project was tabulated (Table 6). Since January 2012, FMD vaccination was implemented in the 10 provinces of Phongsali, Bokeo, Luang Namtha, Oudomxay LPB, XYL, XK, HP, Vientiane and Xaisomboun, covering 401 and 713 villages in the 2012 and 2016 rounds of vaccination, respectively, or approximately $21.8 \%( \pm 7.9)$ of the total villages of the 10 participating provinces. All the vaccines were administered according to the manufacturer instructions by use of conventional syringes, with animals restrained individually using bleeding poles.

The number of cattle and buffalo vaccinated for FMD between January 2012 and December 2016 was determined (Fig. 1) providing an average annual combined vaccination for cattle and buffalo of $270704( \pm 88448)$. The number of animals vaccinated for FMD peaked in the period of August 2014 to February 2015, when over 370000 cattle and buffalo were vaccinated.

The records of FMD outbreaks in the FMD vaccination sites and in northern Lao indicated the last recorded occurrence of FMD was in May 2013, although there were anecdotal reports of minor outbreaks of FMD occurring in central Laos in May 2015 and in northern Lao in Jan 2017.

\section{Discussion}

This study assessed the attitudes of smallholder farmers towards the large-scale FMD vaccination programme, plus changes occurring in smallholder household finances participating in The FMD Vaccination Project implemented in northern and central provinces of Laos between 2012 and 2016. It provides important information, indicating the majority of the farmers with cattle and buffalo appreciated this first large-scale FMD vaccination programme to implement in Laos, occurring at a time when positive financial benefits from their livestock were being accrued by these households during the 4-year period of the vaccination. A previously published partial budget analysis suggested that FMD vaccination programmes in Laos are likely to be cost-effective, with each dollar invested potentially achieving US $\$ 5.3$ in benefits [17], with net benefits at the smallholder farmer level of US $\$ 22$ for cattle and US\$33 for buffalo, following biannual FMD vaccination [9]. Further, an earlier hypothetical study of the annual benefits of a regional FMD control programme involving vaccination in SEA, were estimated to exceed US\$70 million per annum, with a benefit cost ratio of 3:1 considered to outweigh the costs involved in achieving potential FMD freedom with vaccination by 2020 [18].

Vaccines are important in managing FMD as they assist in the suppression of virus transmission and debilitation of animals from clinical FMD, where oral and pedal vesicular lesions lead to inappetance and weight loss. Importantly, infected vaccinated animals excrete lower viral loads, limiting environmental contamination and subsequent challenge to naïve animals [19]. A field study conducted in 2009 of an extensive FMD outbreak in the Lao northern province of XK indicated that morbidity rates for a fully FMD vaccinated, compared with a partially vaccinated (50\%) and unvaccinated, villages were $1.0 \%, 7.9 \%$ and $74.3 \%$, respectively [20]. However, with increasingly dynamic livestock trade in the GMS and beyond, the risk of changes in circulating FMD serotypes appears to be increasing and as there is a limited cross-protection between FMDv serotypes, knowledge of the currently circulating serotypes is critical in the choice of vaccine(s) to use in the control of FMD $[14,21]$. While several serotypes of FMDv can be included in a single vaccine, protection from all strains within those serotypes is not guaranteed [21, 22]. Recent outbreaks of FMD serotype $\mathrm{O}$ in northern and southern Laos in 2017 and 2018 (unpublished) and serotype O/ME-SA/ Ind-2001d in April-May 2015 in Naxaythong district, Vientiane Capital in Laos, and Vietnam and Myanmar [10], plus serotype $A$ in several countries in the GMS, have raised concerns of increasing risks of FMD due to use of vaccines that may offer limited protection against emerging serotypes [14]. Preliminary evidence from investigations of the outbreak of O/ME-SA/ Ind-2001d in Laos suggests that transmission of FMD into the country is likely to have occurred due to movement of animal products from countries beyond the GMS.

This study provides evidence that a large FMD vaccination programme was well regarded by the participating smallholder farmers with the majority of the farmer indicating their willingness to contribute US\$0.5 per dose to the cost of future FMD 
Table 2. Smallholder household income and their livestock, by province and gender of respondent categories

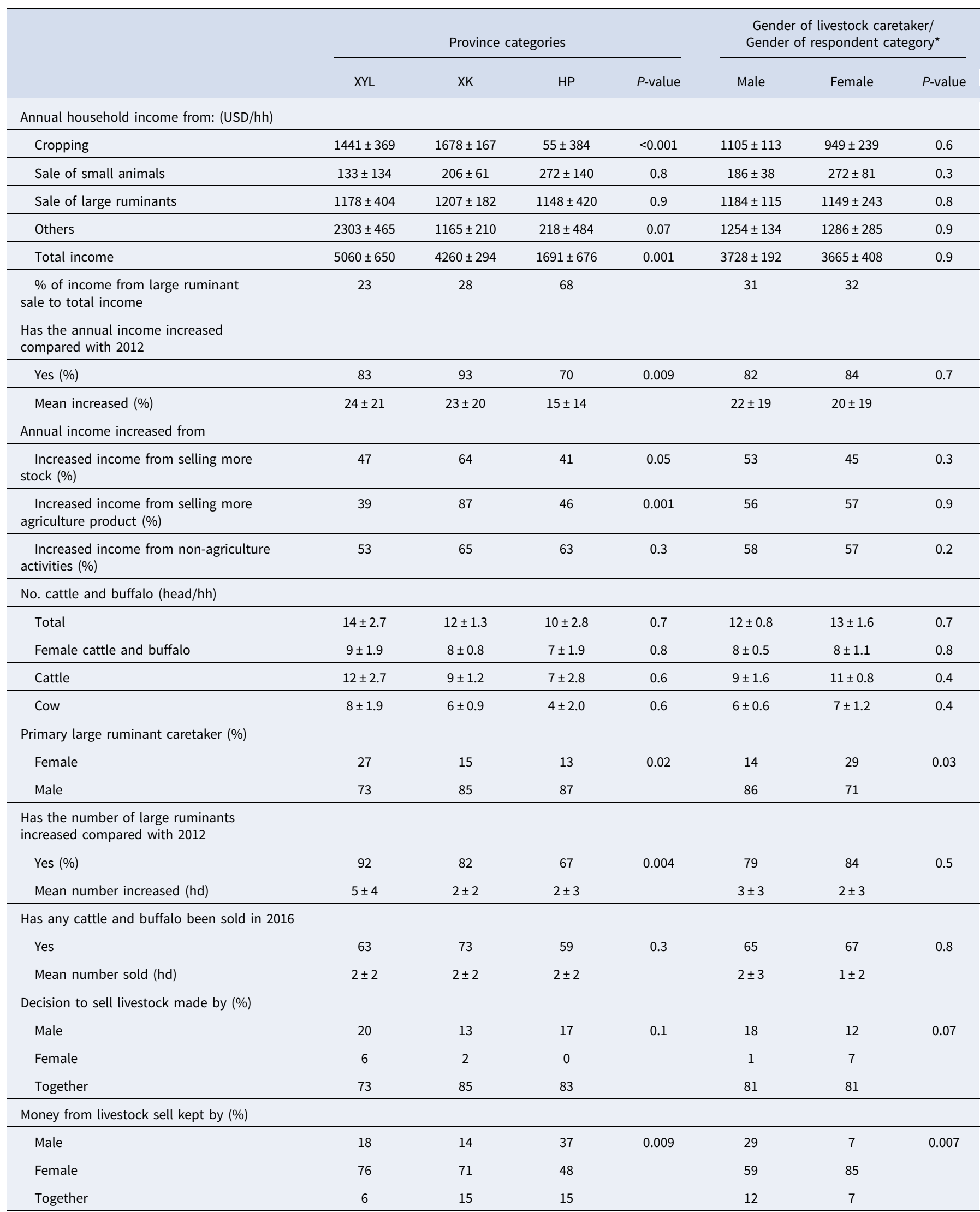

XYL, Xayyabouli; XK, Xiengkhoung; HP, Huaphan; hh, household; hd, heads.

Predicted means \pm standard errors, mean \pm standard deviation.

*Annual household income and mean large ruminants were compared between gender of livestock caretaker whereas other variables were compared between gender of respondent category. 
Table 3. Smallholder farmer knowledge, attitudes and practice responses towards FMD vaccination programmes, by region and gender of respondent categories

\begin{tabular}{|c|c|c|c|c|c|c|c|}
\hline & \multicolumn{4}{|c|}{ Province categories } & \multicolumn{3}{|c|}{ Gender respondent categories } \\
\hline & XYL & $\mathrm{XK}$ & $\mathrm{HP}$ & $P$-value & Female & Male & $P$-value \\
\hline \multicolumn{8}{|l|}{$\begin{array}{l}\text { Farmer knowledge on basic biosecurity } \\
\text { practices }(/ 7)\end{array}$} \\
\hline Morbidity and mortality in the herd reduced & 83 & 87 & 80 & 0.6 & 80 & 92 & 0.5 \\
\hline \multicolumn{8}{|l|}{ Ranking FMD vaccination (\%) } \\
\hline Very good & 67 & 71 & 74 & 0.4 & 68 & 78 & 0.5 \\
\hline Good & 26 & 15 & 20 & & 20 & 20 & \\
\hline Yes (\%) & 100 & 96 & 98 & 0.3 & 97 & 100 & 0.3 \\
\hline Mean amount willing to pay (US\$) & $0.8 \pm 0.5$ & $0.5 \pm 0.3$ & $0.6 \pm 0.6$ & & $0.6 \pm 0.4$ & $0.6 \pm 0.5$ & \\
\hline \multicolumn{8}{|l|}{$\begin{array}{l}\text { Stock vaccinated for FMD in } \\
\text { the last } 6 \text { months }\end{array}$} \\
\hline Yes $(\%)$ & 92 & 91 & 98 & 0.2 & 96 & 88 & 0.06 \\
\hline Mean animal vaccinated & $8 \pm 6.0$ & $7 \pm 4.2$ & $7 \pm 5.2$ & & $7 \pm 5.4$ & $6 \pm 5.2$ & \\
\hline$\%$ of the total adults & $78 \pm 32$ & $87 \pm 38$ & $92 \pm 21$ & & $89 \pm 29$ & $77 \pm 35$ & \\
\hline $\begin{array}{l}\text { Stock vaccinated for FMD regularly } \\
\text { in the last } 4 \text { years (\%) }\end{array}$ & 75 & 85 & 93 & 0.03 & 87 & 78 & 0.1 \\
\hline
\end{tabular}

vaccination programmes, although FMD vaccine and administration costs per unit were between US\$2.1 and US\$2.5. In contrast, the small proportion of the interviewed farmer that ranked the vaccination programme as unacceptable may be a reflection that not all of their large ruminants were vaccinated for FMD. This was a direct result of the vaccination programme design that allowed only one day for vaccination of the whole village, resulting in some of the animals remaining unvaccinated.

Despite the high participation rate, the study identified that farmers had limited knowledge on basic biosecurity practices, with their inability to answer important questions on FMD from the disease description, consistent with a previous study conducted in early 2010 [23]. The current study confirmed the need for improved farmer knowledge of disease awareness and the importance of developing and implementing village-level biosecurity programmes to reduce the current and future risks of FMD outbreaks [14]. Further, lack of institutional credibility and the conflicting priorities of the official veterinary service and smallholder farmers have also been identified as barriers to prompt disease reporting [24].

Significant variation in household income from cropping, non-agricultural activities and total income between province categories was identified in our study, likely reflecting differences in socio-economic development between provinces in Laos $[25,26]$. In the survey sites of XYL and XK, commercial maize cultivation is currently more prominent than in HP, due to high local demand and proximity to markets in Thailand and Vietnam, respectively. Income from the sale of large ruminants of over US $\$ 1,100$ as observed in this study was similar to the US\$1040 reported previously [4]. These findings confirm that income from the sales of large ruminants continues to be very important to smallholder farmer livelihoods, particularly in the low-income households in HP where over half of their annual household income is derived from this trade. Improving cattle and buffalo productivity is increasingly recognised as a national priority in reducing reliance on shifting cultivation and addressing rural poverty in Laos. Programmes that support the development of the smallholder large ruminant sector, including FMD vaccination, offer important opportunities for alleviating rural poverty and food insecurity in impoverished rural communities in Laos [2, 17, 27].

Although the conclusions from this study do not suggest that The FMD Vaccination Project made a direct contribution to the increase of farmer income from large ruminant sales and increase number of large ruminant per household compared with commencement of the project in 2012 , it is very likely that the program has significantly improved large ruminant health in the FMD vaccination areas, reducing the risk of both FMD outbreaks and debilitation of animals from clinical FMD, plus facilitation of safer trade. With estimates of financial losses incurred due to FMD outbreaks in early 2009 of US $\$ 1.7$ per cow for the fully FMD vaccinated village, US\$6.9 for the partially (50\%) vaccinated village and US\$52.4 in the unvaccinated villages [20], it appears that a large opportunity cost is incurred where there is a failure to vaccinate in areas where the risk of FMD incursions is high 
Table 4. Number of total household, household with livestock and their number of livestock vaccinated for FMD in the last 6 months, by province categories

\begin{tabular}{|c|c|c|c|c|}
\hline Variables & $\mathrm{XYL}$ & $\mathrm{XK}$ & $\mathrm{HP}$ & Overall \\
\hline \multicolumn{5}{|l|}{ Mean households (hh per village) } \\
\hline Total households & $210( \pm 70)$ & $96( \pm 60)$ & $88( \pm 34)$ & $113( \pm 78)$ \\
\hline Households with cattle and buffalo & $136( \pm 47)$ & $84( \pm 55)$ & $50( \pm 31)$ & $90( \pm 55)$ \\
\hline Households with cattle and buffalo participating in the FMD vaccination & $56( \pm 27)$ & $53( \pm 27)$ & $37( \pm 24)$ & $49( \pm 25)$ \\
\hline Household with cattle and buffalo participation rate (\%) & $43( \pm 18)$ & $66( \pm 7)$ & $75( \pm 13)$ & $62( \pm 9)$ \\
\hline \multicolumn{5}{|l|}{ Mean number of cattle and buffalo (hd per village) } \\
\hline Total & $796 \pm 394$ & $444 \pm 222$ & $335 \pm 181$ & $525 \pm 327$ \\
\hline Cattle and buffalo aged $>6$ months & $642 \pm 312$ & $360 \pm 178$ & $273 \pm 146$ & $425 \pm 261$ \\
\hline No. cattle and buffalo vaccinated for FMD & $286 \pm 144$ & $257 \pm 145$ & $192 \pm 99$ & $245 \pm 129$ \\
\hline Vaccination rate $(\%)$ & $44 \pm 3$ & $69 \pm 13$ & $73 \pm 10$ & $62 \pm 16$ \\
\hline \multicolumn{5}{|l|}{ FMD outbreaks } \\
\hline Latest FMD outbreaks report (year) & 2012 & 2012 & 2012 & 2012 \\
\hline Mean FMD outbreaks 2006-2016 & 2 & 1 & 1 & 2 \\
\hline Report the case & Yes & Yes & Yes & Yes \\
\hline Means days reporting after knowing the case & $2 \pm 1$ & $4 \pm 3$ & $5 \pm 1$ & $3 \pm 2$ \\
\hline
\end{tabular}

XYL, Xayyabouli; XK, Xiengkhoung; HP, Huaphan; hh, household; mth, months; hd, heads. Mean \pm standard deviation.

Table 5. Doses, source and type of FMD vaccines available 2012-2016

\begin{tabular}{lccl}
\hline Years & $\begin{array}{c}\text { Doses of FMD } \\
\text { vaccines }\end{array}$ & Source & Type of vaccine \\
\hline $2012-13$ & 620000 & OIE STANZ & Bivalent O and A \\
\hline $2012-14$ & 400000 & OIE JTF & $\begin{array}{l}\text { Monovalent O } \\
\text { and } A^{\text {a }}\end{array}$ \\
\hline $2014-16$ & 600000 & OIE STANZ & Bivalent O and A \\
\hline Total & 1620000 & & \\
\hline
\end{tabular}

${ }^{\mathrm{a}}$ These vaccines were only used in the provinces of XK and Vientiane.

and biosecurity awareness is low. Studies in northern Laos and southern Cambodia indicated that FMD caused financial losses to smallholders of $11 \%$ and $60 \%$ of their household annual income, respectively $[9,28,29]$. The major contributors to these financial losses due to FMD were losses due to morbidity, followed by the cost of treatment especially with antibiotics, plus mortalities in mainly young animals $[9,20]$.

This survey showed that over $75 \%$ and $93 \%$ of the interviewed farmers in XYL and HP said that their stock were vaccinated for FMD in the last 4 years, with over $62 \%$ of the adult cattle and buffalo at the village levels vaccinated for FMD in the last round of vaccination. This confirmed suspicions that not all adult animals received FMD vaccination and that some livestock were not regularly vaccinated for FMD during the last 4 years. It is also likely that the numbers of animals vaccinated may have been overestimated, particularly as in the early years of The FMD Vaccination Project, the recording system for numbers of animals vaccinated was not well established. In XK province where the monovalent vaccines were used initially, it is also likely that many animals were not vaccinated with both serotypes $\mathrm{O}$ and A. Further, it is considered that protection of the large ruminant population by vaccination can be undermined by the rapid turnover of animals leading to the decline of herd immunity [30, 31], with high rates of trading of cattle from villages in Mekong countries previously reported [27].

Although there were no records of FMD outbreaks in these survey locations since May 2013, it is highly unlikely that sufficient herd immunity was obtained by The FMD Vaccination Project to provide optimal suppression of FMD. Vaccination coverage of $>80 \%$ of herds to achieve an expected protection of $>75 \%$ of animals (when sera from a group of 16-month-old revaccinated animals are examined) has been suggested as a desirable goal for FMD vaccination programmes [21,31]. Effectiveness of vaccines and vaccination coverage are considered equally critical issues for successful FMD vaccination programmes $[30,31]$, as are efficiency of vaccine administration procedures and improvements in biosecurity [11]. Observations during The FMD Vaccination Project were that biosecurity training could not be delivered effectively to farmers during the vaccination procedures, largely due to both the limited time available because of the slow vaccine administration required where animal-restraint equipment is very basic (bleeding poles), and low smallholder herd numbers, requiring numerous farmers to be involved in assembling the village herd for the vaccination day. However importantly, the results of this study provide evidence that despite compromising their time for other farming activities, almost all farmers were supportive of the programme with many interested in making a financial contribution to the cost of future FMD vaccinations.

Obtaining and maintaining the trust of all stakeholders is critical for sustainable support of FMD vaccination programmes. This can be achieved by ensuring vaccine administration is optimal and using high-quality, efficacious FMD vaccines (multivalent if required) that are appropriate for the circulating serotypes, as identified by virological and serological studies enabling vaccine matching. Further, regular examination of the field efficacy of vaccine(s) in use, by serological methods that differentiate 
Table 6. Number of provinces, districts and villages participating in the FMD vaccination programme, January 2012-December 2016

\begin{tabular}{|c|c|c|c|c|c|c|c|}
\hline $\begin{array}{l}\text { FMD } \\
\text { vaccination } \\
\text { period }\end{array}$ & $\begin{array}{c}\text { No. } \\
\text { participating } \\
\text { provinces }\end{array}$ & $\begin{array}{l}\text { No. total } \\
\text { districts in } \\
\text { participating } \\
\text { provinces }\end{array}$ & $\begin{array}{c}\text { No. total } \\
\text { villages in } \\
\text { participating } \\
\text { provinces }\end{array}$ & $\begin{array}{c}\text { No. } \\
\text { vaccination } \\
\text { districts }\end{array}$ & $\begin{array}{c}\text { No. } \\
\text { vaccination } \\
\text { villages }\end{array}$ & $\begin{array}{l}\text { Vaccination } \\
\text { coverage by } \\
\text { districts (\%) }\end{array}$ & $\begin{array}{l}\text { Vaccination } \\
\text { coverage by } \\
\text { villages (\%) }\end{array}$ \\
\hline $\begin{array}{l}\text { Jan 2012- } \\
\text { Feb } 2013\end{array}$ & 8 & 64 & 4014 & 36 & 401 & 56 & 10 \\
\hline $\begin{array}{l}\text { Feb 2013- } \\
\text { Jun } 2014\end{array}$ & 10 & 80 & 4152 & 68 & 1193 & 85 & 29 \\
\hline $\begin{array}{l}\text { Augt 2014- } \\
\text { Feb } 2015\end{array}$ & 10 & 80 & 4152 & 60 & 1040 & 75 & 25 \\
\hline $\begin{array}{l}\text { Mar 2015- } \\
\text { Dec } 2015\end{array}$ & 10 & 80 & 4152 & 59 & 1143 & 74 & 28 \\
\hline $\begin{array}{l}\text { Jan } 2016- \\
\text { Dec } 2016\end{array}$ & 9 & 75 & 4057 & 29 & 713 & 39 & 18 \\
\hline Mean & & & & 50 & 898 & 65.7 & 21.7 \\
\hline S.D. & & & & 17 & 335 & 18.3 & 7.9 \\
\hline
\end{tabular}

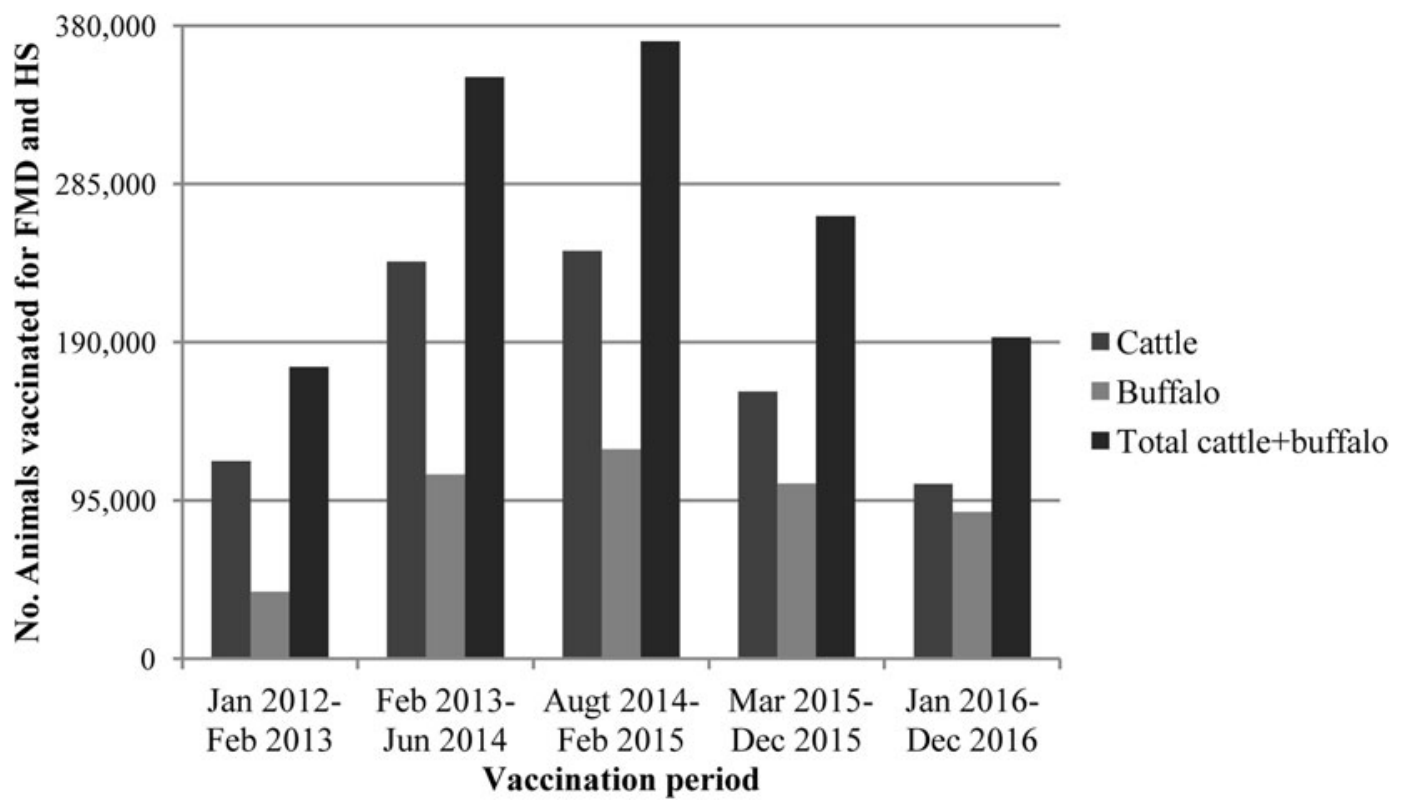

Fig. 1. Total number of cattle and buffalo vaccinated for FMD between January 2012 and December 2016.

infected from vaccinated animals (DIVA) during FMD outbreaks $[32,33]$, is advisable. Research knowledge gap analysis and direction of FMD vaccine development and use have been recently reviewed and indicate that independent evaluation of vaccine quality and monitoring of field protection to improve FMD vaccination control programmes are required [22]. Recent results of FMD vaccination monitoring in XK in Laos demonstrate that FMD serotype $\mathrm{O}$ vaccines induced appropriate response against FMD that were detectable even 15 months after the second vaccination [34]. This suggests that appropriate responses that protect against FMD are very likely to have been achieved in The FMD Vaccination Project sites, although this post-vaccine monitoring work is continuing and completed results are yet to be compiled.

Epidemics of FMD appear to occur in SEA every 5-7 years $[7,8]$. A severe FMD epidemic occurred in northern Laos and beyond in 2010-2012 [3,8], with numerous new outbreaks occurring in many neighbouring countries recently [14] but apparently not in the northern provinces of Laos where The Vaccination Project occurred. With continuation of 'informal' livestock trade in the GMS, it is considered important to continue FMD vaccination in the region, conducted every 5-6 months and particularly in FMD 'high-risk' areas where FMD incursions may occur but outbreaks can be prevented by vaccine-induced suppression of FMDv $[11,12]$. Continuation of FMD vaccination in northern and central Laos for at least another 2-3 years is advisable, ensuring that the momentum of FMD control in the region is sustainable and contributes to the suppression of potential outbreaks, particularly should prevention of FMD transmission and disease by attempted improvements in biosecurity fail. Continuation of FMD vaccination, improved surveillance with serological monitoring and FMD recording, plus enhanced biosecurity and response capability, are crucial to providing sufficient evidence for a potential application to OIE for an FMD free with vaccination zone in northern and central Laos, plus progression of Laos on the Progressive Control Pathway for 
FMD in the future $[35,36]$. It is noted that even with high-potency FMD vaccines with efficacies of $81-98 \%$, suggestions are that vaccination should be conducted every 2.5 months, as beyond this period, vaccine efficacy will decline $[22,36,37]$. However, such an intensive regimen is unlikely to be practical in Laos due to limitations of vaccine funding, availability of human resources, plus the level of farmer participation and access to villages.

It is also widely acknowledged that in achieving more effective disease control, vaccination strategies should be supplemented with other disease control interventions, including improved biosecurity with animal movement control and quarantine, enhanced surveillance and reporting, plus public awareness campaigns that address FMD transmission risks [11, 14, 30]. Multiple interventions that improve large ruminant health and production and motivate interest in disease risk management through improved biosecurity $[3,8]$ are important in driving change in smallholder livestock production [27]. In addition, the identification of FMD high-risk areas ('hotspots and nodes') to enable more strategic use of vaccine, plus determination of the optimal number of vaccination rounds per year for smallholders, is highly recommended [11]. Further, regular active surveillance such as 'negative FMD reporting', immediate reporting of suspected new cases of FMD with development of an emergency response capacity to more effectively manage and limit outbreaks, regular laboratory confirmation of isolates for vaccine matching, plus provision of funding and human resources, are critical in achieving the best-practice FMD control strategies [11, 14, 38]. A number of these activities (e.g. 'negative FMD reporting') have been incorporated in the current national FMD control programme for Laos [39].

It is increasingly acknowledged that women have a very important role in managing rural family livelihoods and in caring for cattle and buffalo in Lao rural communities $[4,8,40]$. This survey identified that $14-29 \%$ of the interviewed farmers claimed that their livestock were managed by women, either the wife or an elder female member in the family. Further, $59-85 \%$ of the farmers indicated that women have a significant role in managing household finances, an observation similar to (or only slightly lower than) previously published observations [4]. This confirms that current and future extension activities requiring consideration of investments from household finances, such as purchase of vaccines, should encourage increased participation by women.

This study provides evidence that a large strategically targeted ongoing FMD vaccination programme was well regarded by the farmers, and despite not achieving optimal vaccination coverage and occurrence of some anecdotal reports of FMD occurring in central Laos, it may have provided sufficient suppression of FMDv to enable widespread protection from detectable disease outbreaks. Reflections on experiences from The FMD Vaccination Project identified numerous lessons learned of relevance to future FMD control and eradication programmes in SEA. This includes further attention to vaccination procedures to optimise herd immunity, increase vaccination coverage, enhance farmer participation plus ensure vaccine matching to enable protection against all current and emerging FMD isolates. In addition, lessons learned that could ensure that the momentum of FMD control in northern and central Laos is sustainable include:

- continuation of the vaccination programme every 5-6 months for at least another 2-3 years, particularly in targeted FMD high-risk areas;

- increasing vaccination days from 1 to 2-3 days per village to enable most of the adult cattle and buffalo in the village to be vaccinated (this aims to increase vaccination coverage based on the observation that a field vaccination day would manage to vaccinate a maximum of 100-200 animals per day).

- increasing FMD vaccine availability and vaccination coverage, by providing FMD vaccines for village veterinary workers to continue vaccination in their villages (one or two $100 \mathrm{cc}$ FMD vaccine bottles);

- provision of improved animal restraint facilities (supplementing the use of bleeding poles with portable yards and animal crushes) and superior vaccination equipment (using vaccine guns with protective sheaths to minimise self-administration) for district vaccination staff and village veterinary workers;

- consideration of payment of vaccinating staff by numbers of animals vaccinated per day or per trip (rather than a set per diem as used currently);

- improving the current data management system (i.e. number of adults animal in each village and district) to enable more reliable determination of FMD vaccination coverage;

- improved animal movement control and biosecurity practices including law enforcement for live animal and their products movement;

- strengthening active and passive disease surveillance and disease reporting at the village, district, provincial and national levels;

- continuation of two-stage random sampling serosurveys to provide increasing evidence of FMD control, eventually supporting a potential FMD-free zone with vaccination application to OIE;

- continuation of sampling and testing strategies to evaluate postvaccination responses and ensure the importance of vaccine matching against emerging isolates is maintained;

- continuation of training programmes for vaccination staff and farmers on basic biosecurity to limit the risk of FMD transmission;

- increased attention to improve biosecurity in addition to vaccination, with biosecurity training programmes for farmers required and preferably delivered separately from the vaccination (due to time constraints);

- improved public awareness of FMD risks, transmission and prevention; plus provision of other production improvement interventions (e.g. forage plantation and utilisation, parasite control, farmer knowledge and practice training) to enhance livelihoods from livestock and generally promote a risk management philosophy throughout all levels of the livestock husbandry system in Laos and beyond.

Supplementary material. The supplementary material for this article can be found at https://doi.org/10.1017/S0950268818002443.

Acknowledgements. The study was conducted in compliance with State Acts and National Codes of Practice for Ethical Standards, with animal and human ethics approval obtained from The University of Sydney Ethics Committee (project no. 2015/765 and 2014/783, respectively). Financial support was from the OIE Sub-Regional Representation for South-East Asia (SRR-SEA) and the Australian-funded Stop Transboundary Animal Diseases and Zoonoses (STANDZ) programme, with some additional support from the Australian Centre for International Agricultural Research (ACIAR project $\mathrm{AH} / 2012 / 067)$. The authors would like to acknowledge the collaboration from the staff of the SRR-SEA and provinces of Xayyabouli, Xiengkhoung and Huaphan, plus the assistance of Mr Kong Khambounheung, Ms Bounxay Kinnavong and Ms Somly Chanda. The genuine hospitality and participation of all interviewed farmers, village chiefs and veterinary workers was greatly appreciated.

Conflict of interest. None. 


\section{References}

1. Rushton J (2009) The Economics of Animal Health and Production. Oxfordshire, UK: CAB International.

2. Windsor PA (2011) Review - perspectives on Australian Animal Health Aid Project in South-East Asia. Transboundary and Emerging Diseases 58, 375-386.

3. Nampanya S et al. (2015) Financial impact of Foot and Mouth Disease on large ruminant smallholder farmers in the Greater Mekong Sub-region. Transboundary and Emerging Diseases 62, 555-564.

4. Nampanya $\mathbf{S}$ et al. (2016) Household financial status and gender perspectives in determining the financial impact of foot and mouth disease in Lao PDR. Transboundary and Emerging Diseases 63, 398-407.

5. Lubroth J (2002) Foot and mouth disease: a review for the practitioner. Veterinary Clinics of North America: Food Animal Practice 18, 475-499.

6. Paton DJ, Sumption K and Bounma P (2009) Review options for control of foot-and-mouth disease: knowledge, capability and policy. Philosophical Transactions of the Royal Society B: Biological Science 364, 2657-2667.

7. Khounsy S et al. (2009) Short communication: molecular epidemiology of foot-and-mouth disease viruses from South-East Asia 1998-2006 - the Lao perspective. Veterinary Microbiology 135, 4297-4299.

8. Madin B (2011) An evaluation of Foot-and-Mouth Disease outbreak reporting in mainland South-East Asia from 2000 to 2010. Preventive Veterinary Medicine 102, 230-241.

9. Nampanya $S$ et al. (2013) Investigation of Foot and Mouth Disease hotspots in northern Lao PDR. Transboundary and Emerging Diseases 360, 315-329.

10. Qui Y et al. (2017) Emergence of exotic O/ME-SA/Ind-2001d Foot-andMouth Disease viruses in South-East Asia in 2015. Transboundary and Emerging Diseases 65, e104-e112.

11. Windsor PA et al. (2011) Control and eradication of Foot and Mouth Disease in the Bicol surveillance buffer zone in the Philippines. Transboundary and Emerging Diseases 58, 421-433.

12. OIE Sub-Regional Representation for South-East Asia (2011) South East Asia and China Foot and Mouth Disease campaign (SEACFMD) 2020 - a roadmap to prevent, control and eradicate foot and mouth disease freedom (by2020) in South-East Asia and China, 2nd Edn. Available at http://www.srr-seasia-oie.com/uploads/tx_oiedownload/SEAFMD_2020. pdf (Accessed 25 May 2013).

13. Kerr J, Sieng S and Scoize A. (2012) Working with traders to understand livestock movements and spread of animal disease in Cambodia and Lao PDR. In Adam LB, Gray GD and Murray G (eds), Animal Biosecurity in the Mekong: Future Directions for Research and Development. Siem Reap, Cambodia: ACIAR Proceeding 137, pp. 59-64.

14. Windsor PA (2017) Implementing Farm Biosecurity: The Role of Government and The Private Sector. In: Proceedings, 30th OIE Conference of Asia, the Far East and Oceania, Putrajaya, Malaysia. pp. 31-50. Available at https://www.researchgate.net/profile/Peter_Windsor/project/ Mekong-Livestock-Research-2/attachment/5a2475efb53d2fobba415de6/AS: 567604751810560@1512338926642/download/Proceedings+OIE+30th+Con ference+Asia\%2C+Far+East\%2C+Oceania.pdf?context=ProjectUpdatesLog (Accessed 4 December 2017).

15. Lao Statistics Bureau (2016) $4^{\text {th }}$ population and housing census. Ministry of Planning and Investment, Vientiane, Laos. Available at http://www.lsb. gov.la/news.phd?id=27 (Accessed 25 January 2016).

16. Dohoo I, Martin W and Stryhn H (2009) Veterinary Epidemiologic Research, 2nd Edn. Charlottetown, Canada: VER Inc.

17. Nampanya S et al. (2016) Financial impacts of Foot-and-Mouth Disease at village and national levels in Lao PDR. Transboundary and Emerging Diseases 63, e403-e411.

18. McLeod R (2010) Realised and potential economic benefits of the Southeast Asia Foot and Mouth Disease Campaign, eSYS Development Australia. Available at http://aid.dfat.gov.au/Publications/Pages/economicbenefits-southeast-asia-footand-mouth-disease-campaign.aspx (Accessed 25 May 2013).
19. Orsel K and Bounma A (2009) The effect of foot- and-mouth disease (FMD) vaccination on virus transmission and the significance for the field. The Canadian Veterinary Journal 50, 1059-1063.

20. Rast L, Windsor PA and Khounsy K (2010) Limiting the impacts of foot and mouth disease in large ruminants in northern Lao People's Democratic Republic by vaccination: a case study. Transboundary and Emerging Diseases 57, 147-153.

21. Doel TR (2003) Review-FMD vaccines. Virus Research 91, 81-99.

22. Robinson L et al. (2016) Global Foot-and-Mouth Disease research update and gap analysis: 3 - vaccines. Transboundary and Emerging Diseases 63, 30-41.

23. Nampanya $\mathbf{S}$ et al. (2010) Assessment of farmer knowledge of large ruminant health and production in developing village-level biosecurity in northern Lao PDR. Transboundary and Emerging Diseases 57, 420-429.

24. Limon G et al. (2013) Using mixed methods to investigate factors influencing reporting of livestock diseases: a case study among smallholders in Bolivia. Preventive Veterinary Medicine 113, 185-196.

25. Epprecht $\mathbf{M}$ et al. (2008) The Geography of Poverty and Inequality in the Lao PDR. Bern, Germany: Swiss National Center of Competence in Research (NCCR) North-South, University of Bern, and International Food Policy Research Institute (IFPRI).

26. Government of Laos and the United Nations (2009) Millennium development goals progress report Lao PDR 2008, UN House, Vientiane, Lao PDR. Available at http://www.unlao.org/Blog/post/Lao-PDR-MillenniumDevelopment-Goals-Progress-Report-2008-\%28Executive-Summary\%29. aspx (Accessed 25 March 2013).

27. Young JR et al. (2015) Improving smallholder farmer biosecurity in the Mekong region through change management. Transboundary and Emerging Diseases 62, 491-504.

28. Young JR et al. (2013) Assessment of financial impact of Foot and Mouth Disease on smallholder cattle farmers in southern Cambodia. Transboundary and Emerging Diseases 60:166-174.

29. Shankar B et al. (2012) Animal disease and livestock-keeper livelihoods in Southern Cambodia. International Development Planning Review 34. doi: 10.3828/idpr.2012.3.

30. Knight-Jones TJD et al. (2016) Global Foot-and-Mouth Disease research update and gap analysis: 2 - epidemiology, wildlife and economics. Transboundary and Emerging Diseases 63, 14-29.

31. Knight-Jones TJD et al. (2016) Mass vaccination, immunity and coverage: modelling population protection against Foot and Mouth Disease in Turkish cattle. Scientific Reports 6. doi: 10.1038/srep22121.

32. Rodriguez L and Grubmann MJ (2009) Review foot and mouth disease virus vaccines. Vaccine 27, 90-94.

33. Sutmoller P et al. (2003) Review - control and eradication of foot and mouth disease. Virus Research 91, 101-144.

34. Sakamoto K et al. (2016) Efficacy of expired Foot and Mouth Disease O type vaccines in cattle and buffalo in Lao People's Democratic Republic. Japan Agricultural Research Quarterly 50, 163-168.

35. Rweyemamu M et al. (2008) Planning for the progressive control of Foot-and-Mouth disease. Transboundary and Emerging Diseases 55, 73-87.

36. OIE-FAO (2012) The Global Foot and Mouth Disease Control Strategy Strengthening Animal Health System through Improved Control of Major Diseases. Rome, Italy: FAO. p. 43.

37. Hutber M, Kitching RP and Conway DA (1998) Control of foot-and-mouth disease through vaccination and the removal of infected animals. Tropical Animal Health and Production 30, 217-227.

38. Naranjo J and Cosivi $\mathbf{O}$ (2013) Elimination of foot-and-mouth disease in South America: lessons and challenges. Philosophical Transactions of the Royal Society B: Biological Science 3681, 20120381.

39. Department of Livestock and Fisheries (2015) National Foot and Mouth Disease Control Plan of Lao PDR. Vientiane, Lao PDR: Ministry of Agriculture and Forestry, pp. 26-41.

40. Steering Committee for Lao Census of Agriculture (2012) Lao Census of Agriculture 2010/11. Vientiane, Lao PDR: Steering Committee for Lao Census of Agriculture Office. Department of Planning, Ministry of Agriculture and Forestry. 